Revista Brasileira de Hematologia e Hemoterapia

Brazilian Journal of Hematology and Hemotherapy

www.rbhh.org

\title{
Scientific Comment
}

\section{Shed some (sun)light on vitamin D deficiency}

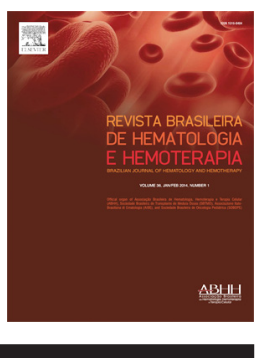

\author{
Adriana Seber* \\ Hospital Samaritano, São Paulo, SP, Brazil
}

We do not read an article that can make us change practice very often. "Vitamin D deficiency in children and adolescents submitted to hematopoietic stem cell transplantation" by Campos DJ from the Curitiba Pediatric Transplantation group is one of these articles. ${ }^{1}$

Although vitamin D deficiency has been the theme of many publications in the last few years, ${ }^{2}$ Brazilians would tend to disregard it as a problem of cold countries, with long winters and low exposure to our beautiful and bright sunshine. But this is not the case. One third of Brazilian children admitted for hematopoietic stem cell transplantation (HSCT) in Curitiba were vitamin $\mathrm{D}$ deficient at admission, and half of them at discharge. Why would any transplant physician worry about it? Because vitamin D deficiency may worsen many of the adverse effects seen after HSCT. These include low calcium and phosphorus blood levels, decreased bone mineral density, chronic bony pain, muscle weakness, impaired immunity, respiratory tract infections, glucose intolerance, and chronic graft versus host disease (GVHD).

In a normal physiology, 7-dehydrocholesterol present in the skin is transformed into vitamin D3 (cholecalciferol) when it is exposed to ultra-violet B light. ${ }^{3-5}$ In the liver, the cholecalciferol and the dietary vitamin $\mathrm{D}$ (ergocalciferol) are transformed into 25-hydroxylase vitamin D3 (25-OH Vit D3 or Calcidiol) and then, in the kidneys, into the only active form, 1,25(OH $)_{2}$ Vit D3 or calcitriol. Many other tissues can also convert $25-\mathrm{OH}$ into $1,25(\mathrm{OH}) 2$ Vit D3 to be locally active. The $25-\mathrm{OH}$ Vit D3 is stored in the body fat, and released when oral intake or sunlight exposure is low.

Dietary sources of vitamin D are scarce: it is present in fish (salmon, sardines, tuna, and cod liver oil), shitake mushrooms and egg yolk. Exposing the skin without sunscreen for half the time that is necessary make an individual erythematous has more than ten times the vitamin $\mathrm{D}$ content of most foods. Exposure of arms and legs for 5-30 min between $10 \mathrm{a} . \mathrm{m}$. and 3 p.m. twice a week is often adequate. The darker the skin, the longer the exposure needed to have the same biological effect. With a sunscreen with sun protection factor 15, there is a $99 \%$ decrease in the production of $25-\mathrm{OH}$ Vit D3. Having a dark skin can be the equivalent to applying factor 8 to 30 to a fair skin. Medications frequently used by HSCT patients, such as anticonvulsants, steroids and antifungals, can further decrease vitamin D levels.

What happens to vitamin $\mathrm{D}$ deficient individuals? The first effect is low intestinal absorption of calcium (only 10-15\%) and phosphorus (about 60\%). Parathyroid hormone (PTH) is secreted in response to the low serum ionized calcium stimulating the kidneys to produce more $1,25(\mathrm{OH})_{2}$ Vit D3. But this mechanism is inefficient if $25-\mathrm{OH}$ Vit D3 tissue levels are low: therefore, PTH increases tubular reabsorption of calcium and stimulates the formation of osteoclasts, which dissolves the bone collagen matrix and releases calcium stores into the circulation, critical to maintain normal circulating calcium values. With this secondary hyperparathyroidism, there is also an increased urinary phosphorus excretion, increased alkaline phosphatase, and decreased bone mineralization, which can progress to osteopenia, osteoporosis and osteomalacia in adults, or rickets with bone deformities in children. Vitamin D deficiency also causes bone and muscle pain and muscle weakness, symptoms that are often misdiagnosed as fibromyalgia or depression.

The active form, $1,25(\mathrm{OH})_{2}$ Vit $\mathrm{D} 3$, is recognized as an immune modulator: while it increases the ability of monocytes and macrophages to kill intracellular mycobacteria, it

DOI of original article: http://dx.doi.org/10.5581/1516-8484.20140029.

* Correspondence to: Rua Botucatu, 743 - Vila Clementino, Universidade Federal de São Paulo (UNIFESP), Instituto de Oncologia Pediátrica (IOP/Graacc), 04023-062 São Paulo, SP, Brazil.

E-mail address: adriana_seber@hotmail.com

http://dx.doi.org/10.1016/j.bjhh.2014.03.017

1516-8484/@ 2014 Associação Brasileira de Hematologia, Hemoterapia e Terapia Celular. Published by Elsevier Editora Ltda. All rights reserved. 
also regulates cytokine production in activated $\mathrm{T}$ lymphocytes and immunoglobulin production by activated B-lymphocytes. In HSCT patients, a small study conducted at the Dana Farber Cancer Institute showed a higher incidence of chronic GVHD in patients with low 25-OH Vit D3 pre-transplant $(64 \%$ versus $24 \%$; $p$-value $=0.009$ ), as well as higher two-year cumulative incidence of extensive chronic GVHD (54\% versus 14\%; $p$-value $=0.005) .{ }^{6}$ Known autoimmune disorders such as multiple sclerosis and Crohn's disease are more prevalent among people who live at higher altitudes and are vitamin $\mathrm{D}$ deficient.

Vitamin D increases myocardial contractility, decreases renin synthesis, decreases blood pressure, and the risk of cardiovascular disease. Vitamin D also increases insulin production and decreases the risk of type 1 and type 2 diabetes and metabolic syndrome.

Cellular proliferation, apoptosis and angiogenesis are also influenced by vitamin D status: $25-\mathrm{OH}$ Vit D3 deficiency is associated with a $30-50 \%$ increased risk of colon, prostate and breast cancer, and higher mortality rates from these tumors. Normal vitamin D levels can reduce the risk of developing non-Hodgkin lymphoma in children and young adults. $^{3-5}$

Vitamin D can be replaced orally as Vit D3 (cholecalciferol), the most potent form, usually present in animal products, or Vit D2 (ergocalciferol) of vegetal origin. It is important to check levels when the patient is suspected of having vitamin $\mathrm{D}$ deficiency, because doses indicated to correct deficiencies may be 25 times higher than usual replacement, and should always include adequate calcium and phosphorus intake. On the other hand, excessive oral vitamin D replacement can lead to intoxication with hypercalcemia, arrhythmias, soft tissue calcification and nephrocalcinosis.

When checking vitamin D levels, the best indicator is $25-\mathrm{OH}$ Vit D3, the main circulating form that has a half-life of two to three weeks. 1,25(OH $)_{2}$ Vit D3 has a half-life of a few hours, and the levels fluctuate more than other forms. The measurement of vitamin $\mathrm{D}$ can be quite expensive, almost 500 reals (more than 200 US dollars) in private Brazilian laboratories.

Importantly, with vitamin D supplementation and fortified foods, American adult and pediatric patients surviving HSCT or acute lymphoblastic leukemia treatment were reported to have an incidence of vitamin D deficiency of about $10 \%$, much lower than Brazilian patients. ${ }^{7,8}$

The magnitude of the vitamin $\mathrm{D}$ deficiency in Latin American countries is unknown. ${ }^{9}$ Brazil may have a high heterogeneity. In Recife, 226 malnourished children were shown to have normal vitamin $\mathrm{D}$ levels, ${ }^{10}$ but in this same region, almost 30 years later, a 31\% prevalence of vitamin D deficiency was shown among elderly men. ${ }^{11}$ A group from Porto Alegre found a $33 \%$ prevalence of vitamin D deficiency in healthy Brazilian girls and demonstrated that it may be associated to specific vitamin D receptor gene polymorphisms. ${ }^{12}$ It would be very interesting to further analyze it in different Brazilian regions, and in patients undergoing HSCT.
In conclusion, the HSCT group from Curitiba showed us convincing data that we should all care about vitamin $\mathrm{D}$, check levels if it is possible, supplement it and keep normal blood values to avoid either worsening of the many transplantrelated side effects or exogenous intoxication. These are new responsibilities for us, and good news for our patients.

\section{Conflicts of interest}

The author declares no conflicts of interest.

\section{REF E R E N C E S}

1. Campos DJ, Biagini GL, Funke VA, Bonfim CM, Boguszewski CL, Borba VZ. Vitamin D deficiency in children and adolescents submitted to hematopoietic stem cell transplantation. Rev Bras Hematol Hemoter. 2014;36:126-31.

2. Simmons J, Sheedy C, Lee H, Koh S, Alvarez J, Koyama T, et al. Prevalence of 25-hydroxyvitamin D deficiency in child and adolescent patients undergoing hematopoietic cell transplantation compared to a healthy population. Pediatr Blood Cancer. 2013;60:2025-30.

3. Holick MF. Vitamin D deficiency. N Engl J Med. 2007;357:266-81.

4. Holick MF. Vitamin D: a D-Lightful health perspective. Nutr Rev. 2008;66 Suppl.:S182-94.

5. Grober U, Spitz J, Reichrath J, Kisters K, Holick MF. Vitamin D: update 2013: from rickets prophylaxis to general preventive healthcare. Dermato-endocrinology. 2013;5:331-47.

6. Glotzbecker B, Ho VT, Aldridge J, Kim HT, Horowitz G, Ritz J, et al. Low levels of 25-hydroxyvitamin $\mathrm{D}$ before allogeneic hematopoietic SCT correlate with the development of chronic GVHD. Bone Marrow Transplant. 2013;48:593-7.

7. Robien K, Strayer LG, Majhail N, Lazovich D, Baker KS, Smith AR, et al. Vitamin D status among long-term survivors of hematopoietic cell transplantation. Bone Marrow Transplant. 2011;46:1472-9.

8. Simmons JH, Chow EJ, Koehler E, Esbenshade A, Smith LA, Sanders J, et al. Significant 25-hydroxyvitamin D deficiency in child and adolescent survivors of acute lymphoblastic leukemia: treatment with chemotherapy compared with allogeneic stem cell transplant. Pediatr Blood Cancer. 2011;56:1114-9.

9. Brito A, Cori H, Olivares M, Fernanda Mujica M, Cediel G, Lopez de Romana D. Less than adequate vitamin D status and intake in Latin America and the Caribbean: a problem of unknown magnitude. Food Nutr Bull. 2013;34:52-64.

10. Linhares ER, Jones DA, Round JM, Edwards RH. Effect of nutrition on vitamin D status: studies on healthy and poorly nourished Brazilian children. Am J Clin Nutr. 1984;39:625-30.

11. Cabral MA, Borges CN, Maia JM, Aires CA, Bandeira F. Prevalence of vitamin D deficiency during the summer and its relationship with sun exposure and skin phototype in elderly men living in the tropics. Clin Interv Aging. 2013;8:1347-51.

12. Santos BR, Mascarenhas LP, Satler F, Boguszewski MC, Spritzer PM. Vitamin D deficiency in girls from South Brazil: a cross-sectional study on prevalence and association with vitamin D receptor gene variants. BMC Pediatr. 2012;12:62. 